\title{
TEACHING LARGE CLASSES
}

\section{QUALITY EDUCATION DESPITE THE ODDS}

\author{
David J Hornsby, Ruksana Osman \& \\ Jacqueline De Matos-Ala
}

\section{INTRODUCTION}

Large-class environments are a reality for many who teach at higher education institutions around the world. Such environments are commonly believed to pose real challenges for educators and students alike: the former, because they seek to deliver a meaningful learning experience; and the latter, because they not only seek to gain knowledge, but also to develop critical thinking skills. Indeed, large classes pose a potential threat to the quality of the educational environment and may have particular ramifications in developing countries, where higher education constitutes a core dimension of the economic and societal development process. The link between quality education and socio-economic development is almost a truism today, and it is safe to assert that quality education is a key component in the development of all countries and can be correlated with improved income levels and economic growth (UNESCO 2005). The provision of quality education is considered to instil key aptitudes and attitudes necessary for economic growth, from essential literacy and numeracy to (equally importantly) motivation and perseverance (UNESCO 2005).

The notion of a citizen who is literate; capable of reasoning with numbers; and enthusiastic about, and able to stick to, the task at hand speaks to a type of person who is an active learner. Active learners think critically about their environment and consider knowledge to be an evolving state of being, where new information can fundamentally refocus one's understanding of and approaches to everyday phenomena. If, then, quality education is in part defined by the presence of these characteristics, how does one instil them in learners in a context that appears to result in the opposite?

This volume seeks to challenge present-day perceptions that large-class learning environments are void of any pedagogical value. As one of the first books of its kind, it guides the reader through the conceptual issues facing large-class teaching in higher education environments, such as the role of the lecture as it relates to large classes. 
This approach is largely rooted in the experiences of scholars and practitioners in developing country contexts, and is interdisciplinary, considering as it does strategies adopted in social and biological sciences, media studies, library sciences, learning support, and education. The insights offered in this book not only address theoretical and conceptual issues, but also provide practical insights for those faced with teaching and supporting large-class environments in higher education.

\section{CONTEXTUALISING THE PROBLEM OF LARGE CLASSES}

There is a long-standing belief that the number of students in a class affects the quality of the learning environment (Ehrenberg, Brewer, Gamoran \& Willms 2001). In particular, large classes are believed to correlate with low student performance. However, class size in and of itself is not a distinguishing feature of student performance; instead, class size matters in relation to education goals and the quality of the educational experience. In higher education, education goals move beyond simple knowledge acquisition to promoting student engagement and higher order cognitive functions - characteristics of deep learning. Here, class size does matter and can affect the quality of student learning (Cooper \& Robinson 2000; McKeachie 1980; MulryanKyne 2010).

Consequently, we define a large class not in terms of a numerical threshold, but rather as an environment where the quality of student learning may be negatively impacted by the number of students in the class. Given the diversity of learning contexts that may exist - varying approaches to and styles of learning, unequal access to teaching and learning support mechanisms, unique disciplinary milieus, and developed vs. developing countries - a large class may be defined in different terms depending on the discipline and/or the pedagogical needs of the learning environment. For example, in theatre studies, any class with more than fifteen students may be considered large, whereas a first-year biology class would be defined as large if the number of students exceeds a hundred; and a higher education institution with limited access to teaching technology may have a different opinion from one with ample technological resources when it comes to what constitutes a large class. While we do not want to discourage assigning numerical thresholds for conceptual purposes (as some of the authors in this volume do), we consider the concept of a large class to be broader and wish to advance an interdisciplinary debate about how to cope with these environments, as opposed to imposing a numerical shackle. Most of the chapters in this volume provide deep insights about fostering teaching and learning in large classes and in varying disciplinary contexts.

Given the clear link between higher education, health, empowerment and economic development (Bloom, Canning \& Chan 2005; OECD 2008; World Bank 2012), there is increasing pressure in many countries to enrol as many students as possible in higher education. Producing more graduates holds both private and public benefits for a country. Private benefits are evidenced by a rise in employment prospects and income, 
and the concomitant ability to invest and save money. Tied as it is to overall better health and longer life expectancy, higher education also leads to improved productivity (Bloom et al 2005). As for public benefits, Bloom and his colleagues catalogue them as follows:

Higher earnings for well-educated individuals raise tax revenues for governments and ease demands on state finances. They also translate into greater consumption, which benefits producers from all educational backgrounds. In a knowledge economy, higher education can help economies keep up or catch up with more technologically advanced societies. Higher education graduates are likely to be more aware of and better able to use new technologies. They are also more likely to develop new tools and skills themselves. Their knowledge can also improve the skills and understanding of non- graduate co-workers, while the greater confidence and know-how inculcated by advanced schooling may generate entrepreneurship, with positive effects on job creation.

(Bloom et al 2005:16)

The trend towards increased enrolment at higher education institutions is also reflected in the South African Department of Higher Education and Training's (DHET) Green Paper on Post-School Education and Training released in early 2012, which envisages enrolments at the country's twenty-three universities to increase from 900,000 per year in 2011 to 1.5 million by 2030, and at other tertiary institutions from 359,000 per year to 4 million over the same period. The express motivation behind this policy is that it will enhance both human and economic development (RSA DHET 2012:20).

However, financial support by governments for higher education is seldom adjusted upward to keep up with the increase in student numbers. On the contrary, budget cuts and fiscal restraint appear to be the global trend, as governments are forced to weigh up the benefits of competing priorities. Thus, as many governments have reduced funding, large classes have become more common due to the limited availability of teaching staff and sheer student enrolment numbers. The greater prevalence of largeclass teaching and learning environments arguably adversely affects the quality of the educational experience, along with student performance, motivation and engagement, and impacts on students' ability to acquire valuable problem-solving and critical thinking skills.

This is especially problematic in the light of research findings that most students enter higher education environments with learning strategies and approaches constructed around the memorisation of facts and the simple reproduction of knowledge, or socalled 'surface learning' (Exeter, Ameratunga, Ratima, Morton, Dickson, Hsu \& Jackson 2010). These students need to be shown how to adopt the problem-solving and critical thinking skills crucial for an innovation economy and a knowledge society (Biggs 1999). Unfortunately, large-class learning environments are typically counterproductive in this regard, as they reinforce didactic teaching styles. The performance of those students who require interaction for motivation is especially likely to suffer when the scope and 
intensity of student-teacher interaction decreases, as tends to happen in large-class environments (Mulryan-Kyne 2010; Exeter et al 2010). Regardless of their learning style, students also exhibit poor levels of engagement with material, less commitment to courses, and lower motivation levels when presented with large classes (MulryanKyne 2010). All things considered, large classes do not appear to be conducive to establishing the higher order cognitive skills noted earlier.

\section{LARGE CLASSES AND DEVELOPING COUNTRIES}

Despite the problems of large-class teaching, it is a reality that many higher education institutions must face as more and more students seek and require degrees in order to secure employment. While this is a problem facing developed and developing countries in equal measure, the issue has higher stakes in developing contexts, for a number of reasons.

Firstly, higher education and access to it are considered as key elements in national development (OECD 2008), which is why increasing student numbers is a key objective in developing countries. However, when students lack motivation or show poor engagement with their subjects and higher order cognitive skills are not fostered, the quality of the learning environment and the educational experience is called into question. As a result, in developing countries, teaching in large-class contexts has direct negative ramifications not only for the quality of the educational experience, but for development per se (UNESCO 2005).

Secondly, the general challenges of large-class teaching are compounded in developing countries in that there are less economic resources available to fund higher education institutions. This means that, in proportion to the population seeking higher education experiences, there are fewer institutions available in developing countries for students to attend, which in turn increases pressure on these institutions to increase intake. For example, Canada has a population of just over 30 million and maintains more than eighty universities; by comparison, South Africa, with its population of over 50 million, has only twenty-three university institutions. In addition, developing countries and their relatively poorer populations have less financial resources with which to provide for and support higher education students, adding further to the pressure to adopt largeclass formats.

Poor student performance (especially among students from vulnerable groups) associated with large classes (Ehrenberg et al 2001; Exeter et al 2010; Mulryan-Kyne 2010) also has more detrimental effects in developing countries. If large classes are associated with higher dropout and failure rates, or students only superficially mastering course content, then they have the potential to reverse the very gains that developing countries hope to achieve by expanding enrolment in the first place. Moreover, in an economic environment that advocates the efficient allocation of resources, this situation represents a waste of scarce government funds. It is therefore essential to adopt practice that mitigates these adverse outcomes in large-class contexts. 
Given the pragmatic reality of large classes, how can developing countries turn this problem into an opportunity? How can quality education, defined as promoting the acquisition of higher order cognitive skills such as problem solving and critical thinking, be achieved in a context that is not conducive to student engagement, motivation, or performance? This book offers both conceptual and empirical insights into ways of ensuring quality education in large-class teaching and learning contexts. It thus fills a considerable gap in the literature by rethinking the opportunities and strategies to promote quality education available to teachers of large classes in higher education environments. Even more importantly, not only does it fill this gap in a manner that is particularly sensitive to the challenges faced by developing countries; it also adopts an interdisciplinary perspective that makes these insights, opportunities and strategies practical and useful for a range of institutional and disciplinary contexts.

The contributors to this book are motivated by the belief that, in and of themselves, large classes do not necessarily spell disaster for student learning or diminish opportunities for providing quality education. The literature contends that students are able to adapt their learning strategies to ensure successful completion of a course (Biggs 1999). Such student resilience and ability to adapt is encouraging, and highlights the important role that teaching and assessment strategies play in student learning (Exeter et al 2010; Meyers \& Nulty 2002; Mulryan-Kyne 2010). Curriculum design, instruction techniques and assessment all influence student engagement and learning outcomes (Biggs 1999; Boulton-Lewis 1998; Kember 1998; Marton \& Booth 1997; Powell 1982; Rowntree 1987). Meyers and Nulty (2002) contend that in order to maximise the quality of students' educational experience, learning environments should be constructed in ways that ensure that students' adaptive responses to the curriculum become congruent with the aims of the course (Biggs 1996; Boud 1982; Ramsden 1992). By focusing on the structure of the curriculum, the strategies employed for instruction, and the way students are assessed, the problems associated with large-class teaching environments can be addressed and quality education ensured (Biggs 1996; Meyers \& Nulty 2002).

This book stems from a two-day symposium held at the Wits (University of the Witwatersrand, Johannesburg, South Africa) School of Education in late 2011 that sought to examine the ramifications of large-class formats for student learning and to present strategies to integrate problem solving, critical thinking and student engagement in these contexts. The symposium attracted a broad range of participants from South Africa and beyond, and was generously supported by the University of the Witwatersrand's Deputy Vice-Chancellor (Academic) Professor Yunus Ballim, as well as the Wits School of Education. The presentations and discussions were driven by a dual desire to understand the unique circumstances of higher education in developing countries and determine whether class size matters in creating a quality educational environment; and if so, to understand how student learning is both affected and effected, and consider what opportunities exist for innovative pedagogical practice. 


\section{CONTRIBUTION}

This is the first book dedicated to exploring the pedagogical value of large classes in higher education systems in developing countries. While there is a rich literature pertaining to education in developing countries, and the connection between education and development in particular, it has tended to focus on primary and secondary education: for instance, Van der Berg and a number of co-authors recently analysed how low-quality schooling in South Africa may act as a poverty trap (Van der Berg, Burger, Burger, de Vos, du Rand, Gustafsson, Shepherd, Spaull, Taylor, van Broekhuizen \& von Fintel 2011). There is also an important and informative body of international literature about the relationship between class size and student achievement at all levels of the education system. A notable contribution by Ehrenberg et al (2001) unpacks the implications of student learning, class size and policy context in the United States' schooling system; while Mulryan-Kyne (2010) provides an insightful analysis of some of the challenges and opportunities associated with teaching large classes at higher education level and offers advice on teaching strategies to enhance lecturing and promote active learning among students, but focuses on countries belonging to the Organisation of Economic Co-operation and Development (OECD).

The present book aims to contribute to the existing literature on development and education by engaging in a discussion about how large class sizes may affect the quality of students' educational experience in countries where higher education is viewed as integral to national developmental objectives. In order to do this, it moves progressively through three themes. Firstly, the lecture and the role of lecture spaces in learning is unpacked and critically analysed to understand some of the conceptual challenges presented by large classes. The lecture is viewed as such an important moment in the learning process that considering it in a critical way is integral to understanding how best to utilise lecture spaces in large-class contexts.

The second theme addresses developing evidence of good practice based on empirical research of effective large-class pedagogy. Accepting that large classes might not be ideal in higher education environments, one must also accept that they are here to stay. Therefore, we need to find ways of turning the challenges of teaching large classes into opportunities.

The third and final theme deals with how best to support large-class teaching in higher education. As the subsequent chapters note, how we construct our learning environments, who we get to teach large classes, and what systems we put in place to help students access information can have a significant impact on student learning.

The chapters that follow also contribute to building an understanding of largeclass pedagogy in higher education in general. It is evident that large classes are an international phenomenon and that no single theory of pedagogy provides the proverbial silver bullet to put all the problems associated with them to rest. However, the majority of the contributors to this book emphasise the need to place student 
learning at the centre of our efforts to mitigate these challenges. Indeed, by placing student learning at the forefront of teaching approaches, we begin to see how they may be turned into opportunities.

Ultimately, the issue of large classes highlights the need to adapt traditional modes of learning, and focuses our attention on how institutions of higher education may best do so. In particular, the chapters offered here address the uptake of lecturers to engage with different modes of learning; the manner in which students want to engage with different learning modes; and the importance of infrastructure in facilitating learning in large-class contexts.

The book also draws attention to a number of different platforms for student learning in higher education and how they either enable or constrain academic staff and students. In particular, the use of technology constitutes a critical way in which people are responding to the challenges posed by large classes, and it is apparent that students are responsive to the present-day technology platforms used in teaching; in fact, it would be fair to say that, having been born into the information age, today's students have always been technologically 'connected'. However, the matter of the effective use of technology by teaching staff remains an issue, as does the availability of appropriate infrastructure. For technology to be a really effective tool, the teaching environment must be set up in such as way as to enable staff and students to easily utilise the latest technological resources.

Finally, the volume reinforces the point that, in order to effectively manage large classes, there has to be a strong commitment to teaching. Given the important connection between education and development, this requires the support of not only higher education institutions, but also of government.

\section{CHAPTER OUTLINE}

This book represents a holistic conversation about the issues pertaining to large classes in a higher education environment: it considers how large classes may be detrimental to student learning, interrogates the types of media that are best suited to promote learning, and presents a wide range of practical approaches taken by lecturers to successfully meet the challenges (many of which are outlined in the first two sections). However, it also goes beyond philosophical discussion and practical teaching and learning debates to address logistical issues related to teaching large classes, such as library resources, budgets, physical learning environments, the equipping of lecturers, and effective use of information technology resources. The fact that it does not seek to divorce discussion about pedagogical issues from logistical considerations is a unique feature of the book, and it is our hope that this inclusive approach will stimulate the production of more integrated research on the subject.

The story told here provides a distinctive perspective on the emerging field of largeclass pedagogy. Adopting a student-centred approach, many of the contributions in 
this volume discuss realistic and achievable ways of modifying curricula and classroom environments in order to enhance the student learning experience. This means that successfully coping with large-class environments does not require a revolution in our approach to teaching, but rather a critical assessment of what we prioritise, how we package our courses, and where support for teaching and learning should be placed. Indeed, the contributions in this volume advance thinking around large-class pedagogy in higher education by drawing particular attention to the prioritisation of student-centred pedagogical models through the use of technology. Of course, technology should not be viewed as the panacea that will solve all problems, but the book details ways in which it may be utilised to ensure that student learning drives higher education environments in developing countries.

The authors invite the reader to move beyond the commonplaces associated with teaching large classes by breaking this large and complex issue down into three themes. Starting with a critical discussion of the concept of 'the lecture' in relation to large classes, the reader is challenged to reflect on how student learning is advanced and whether this traditional vehicle is suited to the task (Chapter 2); what it should look like (Chapter 3); and how technological evolution can help educators in developing contexts (Chapter 4). Accepting that large classes are a reality of many institutions of higher education, regardless of geographic space, consideration is then given to empirical evidence developed by original research into best practices (Chapters 5-8). Finally, acknowledging that large classes require special and differential treatment, the book presents readers with an opportunity to consider structural issues related to supporting these environments (Chapter 9-11).

Chapter 2 confronts traditional conceptions of learning and the best medium to promote learning: the lecture. By rooting his analysis in a history of the lecture in higher education, Alastair Summerlee boldly suggests that we should reconsider the role of the lecture in our efforts to engage students. He contends that lectures are ill-suited to the task of fostering important higher order cognitive skills, yet have nonetheless become the main vehicle for promoting learning; and suggests that in order to cope with large classes, the lecture should become an 'adjunct to learning' and more emphasis be placed on problem-based approaches. In fact, argues Summerlee, if we fail to do this and instead perpetuate the traditional approach to the lecture, we are putting the relevance of higher education at risk.

In Chapter 3, Stephanie Allais adopts the philosophical foundation of Randall Collins' (1998) 'sociology of intellectual change' to argue that contact between lecturers and students is critical to the development and advancement of knowledge. In adopting this approach she highlights the core conundrum of teaching in large classes: the essence of what makes a lecture a valuable learning opportunity is challenged by the extent to which contact time is undermined. Indeed, in developing country contexts, this further disadvantages the already disadvantaged. 
Chapter 4 sets forth a conceptual argument for the use of Open Educational Resources (OER) and other technology in large-class environments. In this chapter, Neil Butcher and Sarah Hoosen argue that the rapid development of Information and Communication Technologies (ICT) globally and in Africa offers both opportunities and challenges for learners who face barriers to traditional means of education delivery. They suggest that utilising technology and engaging with OER may mitigate the negative effects of the growing size of student cohorts and result in a rethinking of the way in which teaching and learning is organised. While they do not advocate abandoning the lecture as a platform for learning, they contend that technology offers flexibility and new opportunities for accommodating student learning strategies outside of the standard classroom.

Chapter 5 signals a shift towards the more empirical component of the book, where specific teaching innovations for large classes are examined in greater detail. In this chapter, Elisabeth Brenner considers the difficulties in teaching large classes at the higher education level, with particular reference to how best to pose questions and receive feedback from students. She shows how technology may be used to connect with students in large classes and to promote deep learning, based on a case study of the introduction of an interactive personal response system, the InterWrite PRS clicker system, into a large second-year Basic Molecular Biosciences class at Wits. The system allows students to respond instantly to a lecturer's questions, thus enabling the lecturer to gauge immediately whether students have understood the relevant concepts and to tailor follow-up lectures to address any gaps in their understanding and knowledge.

Chapter 6 considers the problem of large-class teaching from a social sciences angle, arguing that student engagement is crucial to the development of higher order cognitive skills. Drawing on insights gleaned from a large Introduction to International Relations class, Jacqueline De Matos-Ala and David Hornsby discuss a variety of teaching and assessment techniques. In a sense, the authors combine the conceptual positions put forward in this volume to demonstrate that varied teaching and assessment techniques may help students become active learners. Ultimately, successful promotion of student engagement depends on adapting teaching and assessment techniques to suit deep learning outcomes.

Chapter 7 seeks to advance a way of integrating critical writing in large-class environments. Elisabeth Brenner and Pamela Nichols challenge assumptions about how to foster critical writing and show how the Critical Engagement through Writing (CEW) model has been implemented in large-class environments in South Africa. They describe the theoretical frameworks needed to introduce the model and present a number of practical examples for its implementation, both during and outside of contact periods. The chapter shows that critical writing skills are integral to establishing higher order cognitive skills.

In Chapter 8, Wendy Willems broaches the subject of class participation in largeclass environments. Willems situates her analysis in a post-apartheid South Africa 
that is seeking to balance access to higher education (as a means to address the social inequalities of the past) with promoting a quality educational environment. She explains how blogging can create a 'virtual community of practice' among students in large classes, complementing the physical classroom, and analyses the potential of blogging to promote and enhance critical thinking, participation and student-lecturer interaction in large classes based on her own experience in establishing a magazinestyle blog.

In Chapter 9, Jeff Jawitz builds on the conceptual chapters by considering how the problems associated with large-class teaching relate to the way in which higher institutions support (or rather, do not support) teaching. The author argues that, to compound the problem, those most prepared to teach large classes do not, and contends that large-class teaching will only become effective at fostering higher order cognitive skills once significant changes in institutional attitudes and practices occur. He suggests that more emphasis should be placed on boosting expertise in learning development in order to successfully facilitate learning in large classes. Jawitz also contends that the responsibility for large-class teaching ought to rest with senior academics with a proven track record in their own teaching development, and who are able to mentor junior staff in teaching teams assigned to large classes. Higher education institutions should ensure that these teams are sufficiently well resourced to take advantage of the potential of large-class lectures to excite, motivate and inspire students into pursuing a given discipline.

Chapter 10, by Glenda Myers, focuses on the possibilities for promoting active learning in large-class scenarios. Myers examines how the inclusion of e-resources in the curriculum can improve students' information literacy skills and learning skills, particularly in developing contexts. Based on a Dynamic Purposeful Learning pedagogical model and engagement with librarians, the author discusses ways in which students from disadvantaged backgrounds can improve their information literacy skills - and issue of particular relevance to large-class environments, where instructors are all too often pressed for time and resources.

In Chapter 11, Derek Moore considers the role of the physical construction of the learning environment in large-class pedagogy and discusses how infrastructure and the design of learning spaces matter in the development of student thinking. Drawing on a case study at Wits, the author contends that informal learning spaces (outside the classroom) are often just as important as more formal settings and that, bearing in mind the impact of design and aesthetic decisions on learning, higher education institutions in the developing world should reflect on how they construct their education environments.

Read as a whole, the book represents an attempt to engage the interrelated issues of large-class teaching and country development and to spark a wider debate about teaching, class size, and quality higher education in developing and developed countries alike. More narrowly, it seeks to contribute towards a deeper understanding 
of the challenges of large-class teaching in developing country contexts and to demonstrate how such learning environments may present opportunities for fostering effective problem-solving and critical thinking skills. However, it also warns that significant conceptual and material support is required to make the most of these opportunities, and suggests that those who teach them should perhaps receive special consideration and support. Indeed, given the amount of time and resources required to manage them, large classes can be a real burden in developing contexts; yet, at the end of the day, the development of a country is at stake. 